\title{
Grupo de máes de bebês prematuros hospitalizados: experiência de intervenção de Terapia Ocupacional no contexto hospitalar
}

\author{
Regina Helena Vitale Torkomian Joaquima, Marina Sanches Silvestrini ${ }^{\mathrm{b}}$, \\ Bruna Pereira Ricci Marini ${ }^{\mathrm{b}}$
}

\begin{abstract}
aDepartamento de Terapia Ocupacional, Programa de Pós-Graduação em Terapia Ocupacional, Programa de Mestrado Profissional em Gestão da Clínica, Universidade Federal de São Carlos - UFSCar, São Carlos, SP, Brasil

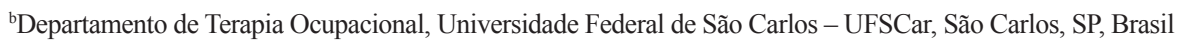

\begin{abstract}
Resumo: A hospitalização do recém-nascido implica em fragilidade para o bebê e para a família, uma vez que ela fica exposta ao estresse e tensões desse momento delicado. $\mathrm{O}$ auxílio que se oferece aos familiares, em especial às mães dos bebês internados, pode refletir nos cuidados futuros à criança, fortalecendo o vínculo e criando um ambiente propício para seu desenvolvimento saudável. Objetiva-se explicitar por meio deste artigo uma experiência junto ao grupo de mães de neonatos hospitalizados. A realização dessa atividade visou promover informação e orientação sobre cuidados e interação dessas mães com seus bebês hospitalizados, prática vivenciada por meio da realização de um Projeto de Extensão em Terapia Ocupacional numa Santa Casa de Misericórdia do interior do estado de São Paulo. Tal atividade, Grupo de Mães, ocorre semanalmente, com o oferecimento de dinâmicas, atividades artesanais, artísticas e plásticas, selecionadas a partir das demandas observadas ou relatadas verbalmente pelas próprias mães nos momentos de encontro no berçário, antes da realização do encontro do Grupo. Como resultado desses encontros grupais, observou-se melhora na condição emocional das mães quando elas participavam do Grupo. Acredita-se que atividades dessa natureza possam facilitar o acesso à informação e orientação para esse público, bem como minimizar o estresse vivenciado pela família diante do contexto hospitalar: estranho e adverso a uma condição natural de nascimento.
\end{abstract}

Palavras-chave: Recém-Nascido, Hospitalização, Orientação, Desenvolvimento Infantil, Terapia Ocupacional.

\section{Group of mothers of hospitalized premature newborns: experience of Occupational Therapy intervention in hospital context}

\begin{abstract}
The hospitalization of newborns implies fragility for the infants and their families, because they are exposed to the stress and tensions of this delicate moment. The support offered to the family, especially to mothers of hospitalized infants, may reflect in the future care provided to these children, strengthening the bond and creating a favorable environment for their healthy development. The objective of this study is to report the experience of occupational therapy in a group of mothers of hospitalized neonates. The aim of this activity was to provide information and guidance on the care and interaction of these mothers with their hospitalized babies. This practice was developed through an Extension Project in Occupational Therapy carried out in a hospital of a countryside city of the state of São Paulo. The Group of Mothers was joined weekly, and dynamics of artisanal, plastic and artistic activities were offered based on the demands observed or reported verbally by the mothers in meetings at the baby nursery before the group was joined. As a result of these group meetings, improvement of the emotional condition of the mothers was observed in the day they participated in the group. We believe that this project can not only facilitate the access to information and guidance to this population, but also minimize the stress experienced by families in the hospital context, which is strange and adverse to a natural birth condition.
\end{abstract}

Keywords: Newborn, Hospitalization, Guidance, Child Development, Occupational Therapy.

Autor para correspondência: Regina Helena Vitale Torkomian Joaquim, Departamento de Terapia Ocupacional, Universidade Federal de São Carlos, Rod. Washington Luís, km 235 - SP 310, CEP 13565-905, São Carlos, SP, Brasil, e-mail: regin@ ufscar.br

Recebido em 29/3/2012; $1^{\text {a }}$ Revisão em 13/11/2012; $2^{a}$ Revisão em 29/4/2013; Aceito em 13/5/2013. 


\section{Introdução}

\subsection{O contexto hospitalar: mães e bebês pré-termo hospitalizados}

A Terapia Ocupacional no contexto hospitalar é uma área que além dos aspectos curativos cuida das relaçóes interpessoais e sociais. Esse ambiente é cercado por diversas questôes complexas como, por exemplo, a biossegurança, a alta rotatividade e a preferência do sistema de saúde pelas intervençôes breves, onde a atuação do terapeuta ocupacional pode facilitar a superação da doença (DE CARLO; LUZO, 2004). Fonseca et al. (2004, p. 67) discorrem acerca de alguns dos princípios presentes nas práticas em saúde no contexto hospitalar:

[...] verticalidade, descontinuidade, predominância da fundamentação biológica, desarticulação de saberes, não participação, enfoque mecanicista e ausência de unidade conceitual.

Frente a essa realidade, comumente identificada no ambiente hospitalar, ressalta-se a importância das iniciativas de cuidado ampliado e integral de apoio e ajuda aos que se encontram nesse ambiente. Nesse sentido, a Terapia Ocupacional pode trazer modificaçóes para esse sistema a partir de seus pressupostos de atuação:

É neste sentido que compreendemos a inserção do terapeuta ocupacional na instituição hospitalar - como um profissional que está atento tanto às características clínicas, necessidades e expectativas relacionadas ao processo de adoecimento, de recuperação da saúde, como também às necessidades psicoafetivas e sociais do paciente e seus familiares e/ou cuidadores (DE CARLO et al., 2006, p. 159).

Uma das atuaçóes da Terapia Ocupacional em ambiente hospitalar é no contexto dos recém-nascidos hospitalizados, ou seja, bebês pré-termo e seus familiares. Bebês pré-termos são aqueles nascidos até o último dia da $37^{a}$ semana de gestação. Esses bebês nascem com uma série de necessidades diferenciadas de cuidado, impostas por sua condição biológica fragilizada, pela restrição ao contato com sua mãe e familiares (BUSNEL, 1997). Os estímulos recebidos pelo bebê em uma Unidade de Terapia Intensiva neonatal (UTIn) ou em um berçário, para onde são encaminhados após a alta da UTIn, são, na maioria, intrusivos e dolorosos (agulhas, sondas, tubos, luzes fortes, alarmes, barulhos), diferenciando-se dos estímulos do ambiente uterino em ritmo, intensidade e qualidade (JOAQUIM, 2000).

Esses bebês ficam em incubadoras, são pequenos, possuem a cabeça relativamente grande se comparada ao corpo e apresentam reflexos mais lentos, embora sejam muito sensíveis a todos os estímulos oferecidos (VIEGAS; MORAES, 1986). Todas essas características podem causar a ruptura do sonho do bebê ideal de toda mulher (KLAUS; KENNELL, 1993). A mulher que acaba de se tornar máe antes do tempo agora encontra-se na angústia de náo estar preparada psicologicamente para a tarefa de maternagem (WINNICOTT, 1980). Tal situação faz com que sinta um vazio, como se tivesse perdido parte do próprio corpo sem acreditar que essa parte é seu novo e diferente bebê, definindo o "luto antecipado", conhecido como fracasso materno (KLAUS; KENNELL, 1993). As mães ficam ansiosas e o contexto estressor gerado pelo nascimento prematuro e a consequente internaçáo pode afetar sua compreensão e raciocínio.

A dificuldade de lidar com essa nova realidade pode fazer com que essa mãe ou cuidadora, que precisa interagir com seu filho e criar um vínculo (BOWLBY, 2002), por ser a mediadora do desenvolvimento dessa criança, acredite ser incapaz de desempenhar até mesmo os cuidados básicos, principalmente aqueles relativos à maternagem, como amamentar, limpar, acarinhar, entre outros (WINNICOTT, 1980).

Ao longo das últimas décadas, essa situação tem suscitado mudanças nas açóes de cuidado e serviços que permitem e estimulam a proximidade da mãe com o bebê e buscam a inserçáo das mães no cuidado, ainda no ambiente hospitalar. A introdução das incubadoras de vidro em 1907, para que a transparência permitisse o maior contato das mães com seus bebês, pode ser considerada um marco no tratamento em neonatologia (KLAUS; KENNELL, 1993). Já a presença familiar nos hospitais, durante as internaçôes, tornou-se lei em 1990 com a promulgação do Estatuto da Criança e do Adolescente, seguindo orientação da literatura sobre a vinculação da criança aos pais e sua importância para o desenvolvimento (DESLANDES, 2008) e para a recuperação dessa criança, que necessita de uma relação contínua e íntima com os pais ou cuidadores (BRAZELTON, 1987)

Em 2000 surge o Programa Nacional de Humanização Hospitalar, atualmente denominado HumanizaSUS, com a finalidade de melhorar $o$ atendimento tanto dos internados quanto dos acompanhantes (CAVALCANTI; GALVÃO, 2007). Mais recentemente, projetos como a Rede Cegonha surgem como tentativas de melhoria da atenção 
hospitalar (estrutura, profissionais capacitados e novas estratégias) para com as gestantes e seus bebês em relação a pré-natal, pós-natal, acompanhamentos, atendimento especial, educaçáo e planejamento reprodutivo e aleitamento, entre outros temas (BRASIL, 2011). Ainda assim, segundo Deslandes (2008), nas UTIn e locais onde são realizados os procedimentos de risco, existe a dificuldade de humanizar o tratamento e permitir a participação dos pais, apesar da situação grave dos bebês. Assim, pelo receio dos profissionais, o que acontece na maioria dos casos é seguir-se o protocolo, no qual há pouca ou quase nenhuma atuação dos pais.

As mães que sentem culpa pelo nascimento antecipado de seus bebês e acham que deveriam ter feito algo diferente ou que cometeram algum erro agora também sentem-se incapazes de cuidar dos próprios filhos, afinal não podem nem embalá-los, como nos anseios da gravidez, o que pode gerar grande frustração (JOAQUIM, 2000). Klaus e Kennell (1993) evidenciam que, na rotina de cuidados hospitalares, a mãe normalmente assume uma posição periférica de apoio, acompanhando os procedimentos médicos e de enfermagem e que, por vezes, nessa situação, pode sentir-se culpada por não saber cuidar de seu bebê com o mesmo desempenho de um profissional. Gaiva e Scochi (2005) avalia que alguns profissionais de enfermagem podem ter uma visão equivocada a respeito da presença da mãe no ambiente hospitalar, ou seja, julgam ser a dela uma presença que pode causar conflitos, atrapalhar a dinâmica do serviço e, assim, reproduzem um comportamento de isolamento e exclusão dessas máes como medida preventiva. Esse ciclo pode gerar, para a genitora, grandes impactos em sua vida emocional, afetiva, profissional e no seu desempenho como mãe (KLAUS; KENNELL, 1993). Para que a mãe seja "suficientemente boa", como sugere Winnicott (1980), entendendo e respondendo de forma adequada aos estímulos de seu filho, ela não pode se encontrar em estado de choque, psicológica e emocionalmente abalada em um nível tão alto, como se não fosse mais capaz de cuidar de seu bebê e nem manter as relações familiares adequadamente. Por todos esses motivos, o apoio à família tem sido apontado como de grande importância para a superaçáo do sofrimento imposto pela hospitalizaçáo do filho, devendo ele ser oferecido pela equipe profissional (DE CARLO; LUZO, 2004; JOAQUIM, 2008) e por grupos de pais (KLAUS; KENNELL, 1993).

A assistência aos pais e a participação da família nos cuidados hospitalares desses neonatos têm sido prioridade nos serviços de neonatologia. O longo período de internação dos bebês e a privação do ambiente aumentam o estresse da mãe e família (SCOCHI et al., 2003, p. 539).

A mediação do desenvolvimento dessa criança depende da mãe (relação entre mãe-bebê) e caso ela esteja em risco, sofrimento emocional, estresse, conflitos internos e externos, ficará mais difícil cuidar efetivamente de si e da criança, portanto há a necessidade de espaços de atuaçáo e cuidado para essas mães e familiares de neonatos hospitalizados (SCOCHI et al., 2003).

A partir das consideraçóes apresentadas, nota-se a importância da realização de ações que possam contribuir para a mudança do paradigma de cuidado a essas mães e seus bebês durante a hospitalização. Afinal

[...] é fundamental que os serviços de neonatologia sejam promotores da qualidade da interação, no sentido de favorecerem a construção e a intensificação do vínculo entre pais e filhos (CAMARNEIRO et al., 2009, p. 54).

Sendo assim, objetiva-se relatar neste artigo uma intervenção em Terapia Ocupacional denominada Grupo de Mães de Neonatos Hospitalizados.

\section{Histórico do Grupo de Mães de bebês hospitalizados}

O Grupo de Mães constitui-se atividade de extensão do Departamento de Terapia Ocupacional vinculada a Pró-Reitoria de Extensão da Universidade Federal de São Carlos. Essa atividade é oferecida a máes de bebês prematuros durante seu período de hospitalização. Os encontros ocorrem semanalmente desde 2003, na Santa Casa de Misericórdia de uma cidade do interior do estado de São Paulo, para as mães lá presentes no dia de realização do Grupo e que queiram participar.

Considera-se que devido às características desse ambiente, as mães necessitam de um acompanhamento para expressarem suas angústias ou mesmo minimizarem as necessidades advindas $\mathrm{da}$ permanência no contexto hospitalar e da dificuldade encontrada em exercer seus papéis sociais, de mães de outros filhos, companheiras, amigas e trabalhadoras. A constituiçáo de grupos pode oferecer abertura para que os integrantes se expressem com liberdade, além de agregar pessoas que têm algo semelhante, histórias de condição de gestante, parturiente e primípara parecidas. É a "caixa de ressonância" na qual o que alguém diz ressoa no outro e o afeta (BRASIL, 2010). 
A experiência apresentada refere-se a um período de cerca de um ano com o Grupo de Mães de Neonatos Hospitalizados. Tal experiência possibilitou resultados significantes quanto ao apoio às mães $\mathrm{e}$ à relação com seu bebê e promoveu a produção de conhecimento acerca do assunto. Ao longo desses anos, as sessôes do Grupo ocorrem semanalmente, com a participação de mães atendidas no berçário pelo Sistema Único de Saúde (SUS), sendo que a participação, em cada sessão, varia de uma a cinco mães.

\section{As visitas ao berçário: compreendendo o contexto}

As mães apresentam aceitação ao Grupo de Mães, contudo sua participação não é constante. Por vezes, as sessóes foram preparadas e as mães não quiseram ou não puderam participar. Essa recusa ocorreu, na maior parte das vezes, quando algum dos bebês internados encontrava-se necessitando de alguma intervenção clínica. Outros motivos relatados por elas são a espera pela visita do médico; o receio de deixar o bebê sozinho; ou a realizaçáo de algum cuidado como banhar ou amamentar o bebê, por exemplo, fora do horário da rotina previamente estipulada pela equipe. Situaçóes como essas caracterizam a rotina diária das mães ou cuidadoras em um berçário hospitalar, o que pode indicar a necessidade de criação de espaços em que as mães possam "dar voz" a essa nova experiência que ora lhes exige açôes de cuidados maternos: amamentação, banho, trocas, entre outros, e ora a espera angustiante por informaçôes, a observação de procedimentos técnicos dolorosos e o uso do tempo em função de um cotidiano que náo é propriamente dela e de seu bebê.

As visitas ao berçário antes do Grupo, então, foram indispensáveis, pois, por meio delas, como observadoras atentas, oferecendo a escuta ativa às máes, as alunas e a coordenadora do grupo puderam perceber a dinâmica do momento e entender do que as máes mais estavam precisando para, por fim, refletir no espaço do Grupo. Assim, fazendo a escolha da atividade, com base nessas informaçóes e com acolhimento, as mães sentiam que no grupo podiam ser compreendidas e se "libertar" da tensão vivida por algumas horas. Mesmo para aquelas máes que não participavam do Grupo, pelas razóes já citadas, somente a escuta e o acolhimento oferecido puderam proporcionar uma melhoria do estado em que se encontravam no berçário: "aqui no berçário posso falar com vocês como mãe de verdade, sem sentir que não sirvo para nada...".

\section{Como desenvolveu-se o Grupo de Mães}

Os encontros aconteciam uma vez por semana com duração de cerca de três horas, incluindo-se aqui a visita ao berçário e a sessão do grupo de Terapia Ocupacional. Primeiramente era realizada a inserçâo no ambiente do berçário, por aproximadamente 40 minutos, considerando a rotina de cuidados e interação das mães com seus bebês e todas as possíveis variáveis desse ambiente como, por exemplo: os procedimentos técnicos de rotina, os procedimentos de emergência, as visitas, a relação máes/profissionais, entre outros. Diante do contexto presenciado eram identificadas as necessidades observadas ou relatadas pelas máes, a partir das quais as atividades eram propostas. Como objetivos, as dinâmicas, atividades expressivas, artesanais e plásticas oferecidas às mães buscavam contemplar o universo descrito na literatura e as observaçóes diretas do contexto hospitalar e proporcionar reflexóes acerca da situação vivenciada pelas mães. A duração da sessão do grupo era de aproximadamente uma hora, sendo coordenada pela docente e observada por uma aluna. Ainda hoje o Grupo é desenvolvido dessa forma.

\section{As atividades propostas e realizadas nas sessões do Grupo}

As atividades propostas pelo grupo têm por intuito oferecer suporte para que as mães possam de uma maneira mais saudável, isto é, mais próxima de um cotidiano reconhecido por elas, enfrentar a situação por elas vivenciada, orientando-as quanto ao cuidar de seus filhos durante e após a alta hospitalar. Dessa forma cria-se um lugar no qual as máes podem expor e compartilhar suas angústias, medos e sofrimentos, de modo a minimizar esses sentimentos, além de poderem nele conversar e refletir sobre como reorganizar seu cotidiano, visualizar redes de apoio, na família ou fora dela, e reconhecer sua autonomia e potencialidade para esse cuidado.

Durante as sessóes eram oferecidas no mínimo duas atividades para as mães, estimulando que elas fizessem sua escolha, evitando assim que fossem tolhidas da possibilidade de exercerem seus desejos no ambiente hospitalar, como ocorre na maioria das vezes, e instaurando um ambiente de possíveis criaçôes e reflexôes. Dentre essas atividades encontram-se: a Caixa-coração, que apresenta diversas questōes relativas a características pessoais e sobre a hospitalização; a Baú dos desejos, na 
qual as mães depositam seus desejos registrados em pequenos papéis; a Pintura de porta-treco; a Colagem de figuras e palavras, significativas a partir de diferentes temas como família, bebê, hospitalização, entre outros; a Quadro de tecidos; a de Recorte e colagem; de Carta ao bebê; de Relato do meu dia no berçário; de Colagem da família; de Montagem da árvore de Natal; do Cartáo de Natal para o bebê"; entre outras. O repertório de atividades foi sendo construído ao longo dos anos de existência do Grupo, elas são constantemente recriadas e analisadas em acordo com as demandas apresentadas por cada máe participante.

Durante a realização dessas atividades nas sessóes do Grupo é que acontece o processo de entender e trabalhar as demandas apresentadas pelas mães: práticas (cuidados do bebê, como fazer "isso" ou "aquilo": dar banho; trocar a fralda; alimentar com copinho; brincar com o bebê; entre outras) e também subjetivas (vivenciar a rotina hospitalar de forma proativa; aproximar-se do bebê; favorecer a ligação mãe-bebê; criar aberturas emocionais para receber esse bebê; vivenciar um espaço de autocuidado e autonomia das mães; entre outras). Por meio do diálogo e da execução das propostas pode-se criar uma interconexão de expressōes, sensações, desabafos e percepçóes sobre si, sobre o outro e sobre essa relação entre todos e, assim, ir tecendo ligaçóes entre diferentes possibilidades: "Pintar isso me fez lembrar de quando era criança, minha infância foi um tempo tão bom..."; "Eu queria falar que amava meu bebê, mas não sabia como, então escrevi no cartão para ele...”; "Nossa, tem muito material, quero usar um pouco de cada um, não conhecia esse aqui, que diferente..."

\section{A opinião e expressão das mães}

A literatura das últimas décadas ressalva que não basta permitir que as mães permaneçam no berçário com seus bebês, que deve-se treinar a equipe para recebê-la e fornecer-lhes suporte no cuidado com seu filho (KLAUS; KENNELL; 1993; MARTURANO; LINHARES; LOUREIRO, 2004; GOMES et al., 1997; JOAQUIM, 2008).

Por meio da observaçáo das atitudes e dos depoimentos dessas máes pudemos perceber o quanto essa intervenção transformava a rotina nesse ambiente durante esse dia, e que as mães sentiam a liberdade de poder se expressar, conversar, desabafar, aguardavam o dia da semana em que o grupo iria acontecer. Na própria sessão, a necessidade das mães por aquele momento era tâo grande que os diálogos, às vezes, eram intensos e longos. Elas recordavam episódios, durante o processo de hospitalização de seus bebês e que estavam ocorrendo em suas casas, com seus familiares, saiam satisfeitas com a atividade produzida e bem mais relaxadas: "O tempo aqui passou de forma leve e muito rápido".

\section{Considerações finais}

O Grupo que tem como foco as mães e suas necessidades e responsabilidades no cuidado com o bebê passou a ser indicado pelas próprias médicas e enfermeiras como espaço diferenciado e único nesse ambiente e contexto para esse público fragilizado. Como aponta De Carlo et al. (2006), a Terapia Ocupacional deve agir como fomentadora de açóes de protagonismo pelos pacientes e cuidadores, dentro do contexto hospitalar, promovendo espaços de melhoria de condição de permanência nesse ambiente e da qualidade de vida dentro e fora do hospital. Essa atividade, o Grupo de Mães de Neonatos Hospitalizados, possibilita um resgate de questôes holísticas e subjetivas na atenção aos sujeitos no contexto hospitalar, produzindo novas formas de se pensar o cuidado: um cuidar mais amplo e abrangente, entendendo as complexidades não somente físicas e curativistas mas contextuais, pessoais e singulares de cada um.

\section{Referências}

BOWLBY, J. Apego, a natureza do vínculo. São Paulo: Martins Fontes, 2002. v. 1. (Trilogia Apego e Perda).

BRASIL. Ministério da Saúde. Caderno Humaniza S.U.S. - atenção básica. Brasília: Ministério da Saúde, 2010. v. 2

BRASIL. Ministério da Saúde. Rede Cegonha (notícia). Brasília: Ministério da Saúde, 2011. Disponível em: <http://portal.saude.gov.br/portal/aplicacoes/noticias/ default.cfm?pg=dspDetalheNoticia\&id_area $=124 \& \mathrm{CO}_{\text {_ }}$ NOTICIA=12362> Acesso em: 28 jun. 2011.

BRAZELTON. T. A dinâmica do bebê. Porto Alegre: Artes Médicas, 1987.

BUSNEL, M. C. A linguagem dos bebês - sabemos escutá-los? Direção de Marie-Claire Busnel. São Paulo: Editora Escuta, 1997.

CAMARNEIRO, A. P. F. et al. Interação mãe-bebê prematuro numa Unidade de Cuidados Intensivos Neonatais. Acta Pediátrica Portuguesa, Lisboa, v. 40, n. 2, p. 53-57, 2009

CAVAlCANTI, A.; GALVÃO, C. Terapia ocupacional - fundamentação e prática. Rio de Janeiro: Guanabara Koogan, 2007. 
DE CARLO, M. M. R. P.; LUZO, M. C. M. (Org.). Terapia Ocupacional - Reabilitação Física e Contextos hospitalares. São Paulo: Editora Roca, 2004.

DE CARLO, M. M. R. P. et al. Terapia Ocupacional em Contextos Hospitalares. Prática Hospitalar, São Paulo, v. 3, n. 43, p. 158-164, jan./fev. 2006.

DESLANDES, S. F. (Org.). Humanização dos cuidados em saúde: conceitos, dilemas e práticas. Rio de Janeiro: Fiocruz, 2008.

FONSECA, L. M. M. et al. Cartilha educativa para orientação materna sobre os cuidados com o bebê prematuro. Revista Latino-Americana de Enfermagem, Ribeirão Preto, v. 12, n. 1, p. 65-75, 2004. http://dx.doi. org/10.1590/S0104-11692004000100010

GAIVA, M. A. M.; SCOCHI, C. G. S. A Participação da família no Cuidado ao Prematuro em UTI Neonatal. Revista Brasileira de Enfermagem, Brasília, v. 58, n. 4, p. 444-448, 2005. http://dx.doi.org/10.1590/ S0034-71672005000400012

GOMES, A. L. H. et al. Mãe-Bebê Pré-termo: as especificidades de um vínculo e suas implicações para a intervenção multiprofissional. Revista de Ginecologia \& Obstretícia, São Paulo, v. 8, n. 4, p. 205-208, out./ dez. 1997.

JOAQUIM, R. H. V. T. Capacitação de mães de bebês pré-termo como agentes de promoção do desenvolvimento, no ambiente hospitalar. 2008. 392 f. Tese (Doutorado Educação Especial)-Universidade Federal de São Carlos, São Carlos, 2008.

JOAQUIM, R. H. V. T. Efeitos da estimulaçâo tátil e auditiva para bebês de alto risco em unidade de terapia intensiva. 2000. 89 f. Dissertação (Mestrado, Individuo Especial)-Centro de Educação e Ciências Humanas, Universidade Federal de São Carlos, São Carlos, 2000.

KLAUS, M. H.; KENNELL, J. H. Pais/bebê: a formação do apego. Tradução de Daise Batista. Porto Alegre: Artes Medicas, 1993.

MARTURANO, E. M.; LINHARES, M. B. M.; LOUREIRO, S. R. (Org.). Vulnerabilidade e proteção: indicadores na trajetória de desenvolvimento do escolar. São Paulo: FAPESP, 2004.

SCOCHI, C. G. S. et al. Incentivando o vinculo mãe-filho em situação de prematuridade: as intervençóes de enfermagem no Hospital das Clínicas de Ribeirão Preto. Revista Latino-Americana de Enfermagem, Ribeirão Preto, v. 11, n. 4, p. 539-43, 2003. http://dx.doi.org/10.1590/ S0104-11692003000400018

VIEGAS, D.; MORAES, R. V. Neonatologia clínica e cirúrgica. Rio de Janeiro: Atheneu, 1986.

WINNICOTT, D. M. A família e o desenvolvimento do individuo. Belo Horizonte: Interlivros, 1980.

\section{Contribuição dos Autores}

As autoras foram responsáveis pela elaboração do texto de forma conjunta. Regina Helena Vitale Torkomian Joaquim: concepção do trabalho, revisão do conteúdo, redação e finalização do artigo. Marina Sanches Silvestrini: organização do conteúdo, redação e finalização do artigo. Bruna Pereira Ricci Marini: organização do conteúdo, redação e finalização do artigo. 